\title{
A study on nephropathy in type2 diabetes individuals in coastal Andhra Pradesh, India
}

\author{
Raja Sekhar A. ${ }^{1}$, Murali Krishna N. ${ }^{2 *}$, Dorapudi B. ${ }^{3}$, Chandra T. ${ }^{4}$
}

DOI: https://doi.org/10.17511/ijmrr.2020.i05.01

\footnotetext{
${ }^{1}$ Avapati Raja Sekhar, Associate Professor, Department of General Medicine, GSL Medical College, Rajahmundry, Andhra Pradesh, India.

2* Nallamothu Murali Krishna, Associate Professor, Department of General Medicine, GSL Medical College, Rajahmundry, Andhra Pradesh, India.

3 Bhaskar Dorapudi, Resident, Department of General Medicine, GSL Medical College, Rajahmundry, Andhra Pradesh, India.

${ }^{4}$ T Jaya Chandra, Scientist in-charge, Central Research laboratory, GSL Medical College, Rajahmundry, Andhra Pradesh, India.
}

Introduction: Diabetes nephropathy (DN) is an important, life-threatening microvascular complication of diabetes mellitus (DM). With this, a study was conducted to find the association between type 2 DM and DN. Materials and Methods: The study was conducted in the department of general medicine, GSL Medical College. Type 2 diabetic subjects who attended the outpatient and inpatient wards, aged > 30 years were included in the study, known renal disease/ were not considered. Albumin creatinine ratio was measured by immune turbidometry using a microalbuminuria test kit provided by ERBA MANHEIM GERMANY. Serum creatinine was done by creatininase enzymatic method, eGFR was calculated using the CKD-EPI equation. $P<0.05$ was considered statistically significant. Results: A total of $150 \mathrm{DM}$ participants were included in the study; mean serum creatinine was $1.59+1.25$ with a range from 0.4 to $8.7 \mathrm{mg} / \mathrm{dl}$ and mean eGFR of the study participants was $73.65+40.428 \mathrm{ml} / \mathrm{min} / \mathrm{m}^{2}$ with a range from 7 to $162 \mathrm{ml} / \mathrm{min} / \mathrm{m}^{2}$. DN was detected in 45\% (67) participants. Conclusions: The present study reveals that there was significant evidence to support that microalbuminuria or proteinuria in patients with diabetes is a potential risk factor not only for kidney function impairment but also as a marker for high risk of cardiovascular complications.

Keywords: Diabetes, Kidney, Microalbuminuria, Nephropathy

\section{Corresponding Author}

Nallamothu Murali Krishna, Associate Professor, Department of General Medicine, GSL Medical College, Rajahmundry, Andhra Pradesh, India. Email: gslcentralresearchlab@gmail.com
How to Cite this Article Sekhar AR, Krishna NM, Dorapudi B, Chandra TJ. A study on nephropathy in type 2 diabetes individuals in coastal Andhra Pradesh, India. Int J Med Res Rev. 2020;8(5):338-343.

Available From

https://ijmrr.medresearch.in/index.php/ijmrr/article/ view/1169
To Browse

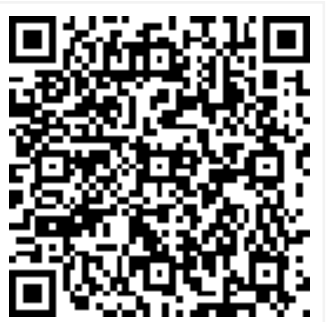

Manuscript Received 2020-03-17

Conflict of Interest No

Review Round 1
2020-03-26
Funding
Nil

Review Round 2 2020-04-10

Ethical Approval Yes
Review Round 3

Accepted 2020-04-30

Plagiarism X-checker $7 \%$

Note

(c) 2020 by Avapati Raja Sekhar, Nallamothu Murali Krishna, Bhaskar Dorapudi, T Jaya Chandra and Published by Siddharth Health Research and Social Welfare Society. This is an Open Access article licensed under a Creative Commons Attribution 4.0 International License https://creativecommons.org/licenses/by/4.0/ unported [CC BY 4.0]. 


\section{Introduction}

Diabetic nephropathy (DN) is the leading cause of end-stage renal disease and the care of patients with diabetes and DN contributes to significant health care costs. Of patients with type 1 diabetes, approximately $20-30 \%$ will eventually develop DN, whereas about $10-20 \%$ of those with type 2 diabetes will do so [1]. India is the diabetes capital with home to 69.1 million people with DM, the second-highest number of cases after China.

Patients with diabetic kidney disease have exceptionally high rates of cardiovascular morbidity and mortality. The excess mortality among patients with diabetes appears to be largely limited to the subgroup with kidney disease and is explained by their high burden of cardiovascular disease. The mechanisms underlying the strong association between diabetic kidney disease and various forms of cardiovascular disease are poorly understood [2].

More recent studies have emphasized the importance of chronic heart failure (HF) as common and deadly comorbidity, to which the patient with nephropathy, even in its earliest stages, is especially prone.

DN is an important and often life-threatening microvascular complication of diabetes mellitus (DM). It is usually first manifested as an increase in urinary albumin excretion (microalbuminuria), which progresses to overt albuminuria and then to renal failure $[3,4]$. With this, a study was conducted to find the association between type $2 \mathrm{DM}$ and $\mathrm{DN}$.

\section{Materials and Methods}

Settings: The study was conducted in the department of general medicine, GSL Medical College.

Duration and Study design: The study was conducted from November 2015 to April 2017. It was a cross-sectional study

Study subjects: Type 2 diabetic subjects who attended the outpatient and inpatient wards of the medicine department in GSL medical college were included in the study.

Sample size: Random sampling was considered in the study; as per this, 150 patients were included in this research.

Inclusion criteria: All type 2 diabetics above the age of 30 years.
Exclusion criteria: Type 2 diabetics with ischemic heart disease, hypertension, and Valvular heart disease, UTIs, poor transthoracic echo window, known renal disease/family history of renal disease were excluded from the study.

Ethical issue: The study was approved by the institutional ethics committee.

Methodology: A pre-structured questionnaire was used to collect clinical data. Baseline data including age, detailed medical history, history, family history, drug history, and personal history were recorded. Clinical examination and routine and relevant investigations were carried out for all participants.

The weight of the subjects was measured to the nearest $0.1 \mathrm{~kg}$ in light clothes on standing barefoot using a well-calibrated balance scale. The height of the subject was measured to the nearest $0.5 \mathrm{~cm}$ using a wooden scale fixed on the wall while the subject is standing relaxed with barefoot and heels together touching the wall.

Waist circumference was measured at the smallest horizontal circumference between the lower costal margin and iliac crest after a normal expiration, and the hip circumference was measured at the point of maximum extension of the buttocks. BMI was calculated as weight in kilograms divided by height in square meters.

Diagnosis of diabetes was made according to WHO criteria or if the subjects were already taking insulin or oral antidiabetic drugs. Criteria for diagnosis of Diabetes mellitus. Subjects with systolic pressure more than $130 \mathrm{~mm} \mathrm{Hg}$ and diastolic pressure more than $90 \mathrm{mmHg}$ or those on antihypertensive drugs were considered hypertensive. Triglycerides $>150 \mathrm{mg} / \mathrm{dl}$ and $\mathrm{HDL}<40 \mathrm{mg} / \mathrm{dl}$ for males and $<50 \mathrm{mg} / \mathrm{dl}$ for females and on specific treatment was taken as dyslipidemia.

Venous blood samples were taken after an overnight fast for fasting blood glucose and 2-hour post glucose blood sugar, glycosylated hemoglobin, and lipid profile. Plasma glucose concentration was estimated using the glucose oxidase method.

Serum lipids (total cholesterol, triglycerides, LDL cholesterol, and HDL plasma cholesterol concentrations) were measured. Cholesterol and triglyceride levels were determined in the serum by commercially available kits on an Erbamannheim -360 analyzer. High -density lipoprotein was measured by using the direct high-density lipoprotein method. 
Low-density lipoprotein and very-low-density lipoprotein cholesterol were calculated according to the formula of Friedewald et al. LDL cholesterol $=$ cholesterol-[HDL cholesterol + (0.46xtriglycerides) $]$

Glycosylated hemoglobin ( $\mathrm{HbA1c}$ ) was estimated by the ion exchange resin method using colorimetry. Albumin creatinine ratio ( $A C R$ ) was measured by immunoturbidometry using the Microalbuminuria test kit provided by Erba manheim, Germany. Serum creatinine was done by creatininase enzymatic method, eGFR was calculated using the CKD-EPI equation.

ECG recording was obtained for every subject to rule out ischemic heart disease. ECG finding of left ventricular hypertrophy was done by using the Sokolow-Lyon index where the sum of $S$ wave in $\mathrm{V} 1$ and $\mathrm{R}$ wave in $\mathrm{V} 5$ or $\mathrm{V} 6>35 \mathrm{~mm}, \mathrm{R}$ wave in $\mathrm{aVL}$ $>11 \mathrm{~mm}$.

Statistical analysis: Statistical analysis was done by using SPSS version 21.0. A Chi-square test was used to assess the association among different categorical variables; $P<0.05$ was considered statistically significant.

\section{Results}

A total of 150 DM participants was included in the study; 79 were male participants and 79 were females (Table 1). Gender-wise, nephropathy was diagnosed in $35(44.3 \%)$ and $32(45.1 \%)$ male and female participants respectively. And nephropathy was not identified in 55.7\% (44) male and 54.9\% (39) female participants. Statistically, there was no significant difference (Table 2).

The mean age of study participants was $56.98+$ 10.27 years and ranged between 30 to 88 years. The mean serum creatinine was $1.59+1.25$ with a range from 0.4 to $8.7 \mathrm{mg} / \mathrm{dl}$ and mean eGFR of the study participants was $73.65+40.428 \mathrm{ml} / \mathrm{min} / \mathrm{m} 2$ with a range from 7 to $162 \mathrm{ml} / \mathrm{min} / \mathrm{m} 2$.

Out of the $150(100 \%)$ study participants, USG findings were normal in $60 \%$ (90) and abnormal findings in the remaining $40 \%$ (60). Among these, $20 \%$ (30) were diagnosed to be grade $1-2,19.3 \%$ (29) as grade $2-3$ and $0.7 \%$ (1) were diagnosed to be grade $3-3$.

Table-1: Gender wise distribution of the study participants

\begin{tabular}{|l|l|l|}
\hline \multicolumn{1}{|c|}{ Gender } & \multicolumn{1}{c|}{ Frequency } & \multicolumn{1}{c|}{ Percent } \\
\hline Female & 71 & 47.3 \\
\hline
\end{tabular}

\begin{tabular}{|l|l|l|}
\hline Male & 79 & 52.7 \\
\hline Total & 150 & 100.0 \\
\hline
\end{tabular}

Table-2: Correlation between gender and nephropathy status in the study population

\begin{tabular}{|l|l|l|l|}
\hline \multirow{2}{*}{ Gender } & \multicolumn{2}{|c|}{ Nephropathy } & \multirow{2}{*}{ Total } \\
\cline { 2 - 3 } & Present & Absent & \\
\hline Female & $32(45.1 \%)$ & $39(54.9 \%)$ & $71(100 \%)$ \\
\hline Male & $35(44.3 \%)$ & $44(55.7 \%)$ & $79(100 \%)$ \\
\hline Total & $67(44.7 \%)$ & $83(55.3 \%)$ & $150(100 \%)$ \\
\hline Chi square $=0.009 ; \mathrm{P}=0.925$ (Non-significant) \\
\hline
\end{tabular}

\section{Discussion}

The prevalence of DN in this study was $44.7 \%$. This was comparable with other studies, the DN prevalence was reported between $29.1 \%$ to $38 \%$. Studies wise, the prevalence were reported to be $29.1 \%$ by Unnikrishnan et al., $39 \%$ in Pataap $\mathrm{K}$ Chandie Shaw et al., report, $29 \%$ by Retnakaran et al. report, $33 \%$ by Wirta et al study, $25.95 \%$ in Collins et al. [5-9].

In another study by Krairittichai $U$ et al., $37.2 \%$ prevalence was reported [10]. From the above data, it was clear that there was a high prevalence of DN in the present study group compared to other studies, which may signify that rise in the diabetic population and early identification of nephropathy through microalbuminuria was needed.

The population with a longer duration of DM was increased prevalence of nephropathy in type 2 diabetes patients. Increased risk of microvascular complications was associated with a longer duration of diabetes.

DN has a greater degree of impairment than is present in nondiabetic kidney disease [11]. A GFR less than $60 \mathrm{~mL} / \mathrm{min} / 1.73 \mathrm{~m} 2$ is consistent with the diagnosis of chronic kidney disease, underlying causes other than DN might be involved in patients with a GFR below $60 \mathrm{~mL} / \mathrm{min} / 1.73 \mathrm{~m} 2$, thus calling for the differential diagnosis between DN and any other potential non-diabetic kidney diseases.

J. Miyazato et al. reported a study on left ventricular diastolic dysfunction in patients with chronic renal failure [12]. In this study 67 patients with nondialysis CRF as a result of chronic glomerulonephritis $(n=33)$ or DN $(n=34)$, and 134 hypertensive patients with normal renal function. The diastolic dysfunction was diagnosed in 41 participants; statistically significant. 
In type 1 diabetes, microalbuminuria is rarely present at diagnosis, but persistent and untreated microalbuminuria will progress to albuminuria in $30 \%-80 \%$ of individuals over $10-15$ years., and of those, $50 \%$ - $78 \%$ will progress to DN over the next 10-18 years [13]. In type 2 diabetes, microalbuminuria and even albuminuria may be present at or soon after diagnosis, in part because diabetes has often already been present for years. In the present study group mean urine albumin creatinine ratio (UACR) was $84.6+70.8 \mathrm{mg} / \mathrm{g}$ $(p=0.0001)$, and the mean serum creatinine was $2.51+1.37 \mathrm{mg} / \mathrm{dl}(\mathrm{p}=0.003)$, and the mean eGFR was $37.54+24.9 \mathrm{ml} / \mathrm{min} / \mathrm{m} 2 \quad(p=0.001)$, which shows that the renal parameters which were mentioned shows statistically significant association with the nephropathy. The above data were compared with other studies like DCCT where gender-specific equations of ACR shows a cut off of microalbuminuria and macroalbuminuria in males was $19.1 \mathrm{mg} / \mathrm{g}$ and $143.5 \mathrm{mg} / \mathrm{g}$, in females was $29.0 \mathrm{mg} / \mathrm{g}$ and $217.4 \mathrm{mg} / \mathrm{g}$, and eGFR mean was $84.5+17.1 \mathrm{ml} / \mathrm{min} / \mathrm{m} 2 \quad(p<0.001)$, and serum creatinine mean was $0.95+0.3 \mathrm{mg} / \mathrm{dl}(p<0.001)$, and these values are found to be significantly associated [14].

In a study by Fisher et al., the mean eGFR was $43+13 \mathrm{ml} / \mathrm{min} / \mathrm{m} 2$ and the median ACR was 46 $\mathrm{mg} / \mathrm{g}$ [15]. In a Japanese study by Yuko Watanabe et al., the mean ACR concerning albuminuria was $261.5 \mathrm{mg} / \mathrm{g}(\mathrm{p}<0.001)$, and for eGFR strata, it was not significantly associated, and in that study mean eGFR and mean serum creatinine when compared to eGFR strata they were significantly associated but concerning albuminuria they were not significantly associated [16], in various other studies like Sanjeev Kumar et al. mean serum creatinine was $1.76+0.59 \mathrm{mg} / \mathrm{dl}(\mathrm{p}<0.0001)$ and was significantly associated with nephropathy [17]. Debbarma et al. reported mean serum creatinine was $1.08+0.18$ $\mathrm{mg} / \mathrm{dl}(\mathrm{p}=0.01)$ and shows a significant association with nephropathy [18]. In Prataap $\mathrm{K}$ et al., study, the mean serum creatinine was $0.86 \mathrm{mg} / \mathrm{dl}$ and shows significant association with macroalbuminuria $(p=0.00093)$ and not significantly associated with microalbuminuria $(p=0.20)$, in Prataap $K$ et al south Asians showed an eGFR of $100 \mathrm{ml} / \mathrm{min}$ and Europeans showed an eGFR of $90 \mathrm{ml} / \mathrm{min} / \mathrm{m}$ [6]. Levey et al. studied the role of eGFR in chronic kidney disease in predicting prognosis, eGFR was one of the important indicators of reserved renal function and indicator of prognosis [19].

\section{Conclusions}

The present study reveals that there was significant evidence to support that microalbuminuria or proteinuria in patients with diabetes is a potential risk factor not only for kidney function impairment but also as a marker for high risk of cardiovascular complications.

\section{Limitation}

Small sample size, short duration are the limitations of the study.

\section{What does the study add to the existing knowledge}

Diabetes is an important risk factor for kidney function impairment, and the observations from the present study do provide significant evidence that suggests microalbuminuria or proteinuria in patients with diabetes is a potential risk factor for kidney impairment and cardiovascular complications.

\section{Author's Contribution}

Dr. Avapati Raja Sekhar: Study design, Literature survey, data analysis, paper writing.

Dr. Nallamothu Murali Krishna: Study design, paper writing.

Dr. Bhaskar Dorapudi: Main work, Literature survey, data analysis

Dr. T Jaya Chandra: Data analysis, paper writing, statistical part.

\section{Reference}

01. Zhenhua He. Diagnosis and Treatment of Diabetic Nephropathy in Type 1 and Type 2 Diabetes Patients. J Mol Biomark Diag. $2016 ; 7 ; 5$.

doi: 10.4172/2155-9929.1000295 [Crossref]

02. Ragnar Pálsson, MD and Uptal D Patel. MD Cardiovascular Complications of Diabetic Kidney Disease Adv Chronic Kidney Dis. $2014 ; 21(3) 273-280$.

doi: 10.1053/j.ackd.2014.03.003 [Crossref]

03. Alvin C. Powers, Diabetes MellitusComplications. Harrison's Principles of Internal Medicine, 19th edition. 2015.

[Crossref] 
04. Mogensen CE, Christensen CK, Vittinghus E. The stages in diabetic renal disease with emphasis on the stage of incipient diabetic nephropathy. Diabetes. 1983;32(2)64-78.

doi: $10.2337 /$ diab.32.2.564 [Crossref]

05. Unnikrishnan R, Rema M, Pradeepa R. Prevalence and risk factors of diabetic nephropathy in an urban south Indian population the Chennai Urban Rural Epidemiology Study (CURES 45). Diabetes Care. 2007;30(8)2019-2024.

doi: $10.2337 / \mathrm{dc06}-2554$ [Crossref]

06. Shaw PK, Baboe F, van Es LA, van der Vijver JC, van de Ree $M A$, de Jonge $N$, et al. South-Asian Type 2 Diabetic Patients Have Higher Incidence and Faster Progression of Renal Disease Compared With Dutch- European Diabetic Patients. Diabetes Care. 2006;29(6)1383-1388. doi: $10.2337 / \mathrm{dc06}-0003$ [Crossref]

07. R Retnakaran Cromme, R Szekessy T. Risk Factors for Renal Dysfunction in Type 2 Diabetes UK- Prospective Diabetes Study. Diabetes. 2006;55(6)1832-1839.

doi: $\quad 10.2337 / \mathrm{db} 05-1620 \quad$ [Crossref]

08. Wirta OR, Pasternack AI, Oksa HH, Mustonen JT, Koivula TA, Helin $\mathrm{HJ}$, et al. Occurrence of late specific complications in type II (non-insulindependent) diabetes mellitus. J Diabetes Complications. 1995;9(3)177-185.

doi: 10.1016/1056-8727(94)00034-I [Crossref]

09. Collins VR, Dowse GK, Plehwe WE, Imo TT, Toelupe PM et al. High prevalence of diabetic retinopathy and nephropathy in Polynesians of Western Samoa. Diabetes Care. 1995;18(8)1140-1149.

doi: $10.2337 /$ diacare.18.8.1140 [Crossref]

10. Krairittichai U. Prevalence and risk factors of diabetic nephropathy among Thai patients with type 2 diabetes mellitus. J Med Assoc Thai. 2011;94(2)1-5.

[Crossref]
11. Hong D, Zheng T, Jia-qing S, Jian W, Zhihong $L$, Lei-shi L. Nodular glomerular lesion- A later stage of diabetic nephropathy?. Diabetes Res Clin Pract. 2007;78(2)189-195.

doi: $10.1016 /$ j.diabres.2007.03.024 [Crossref]

12. Miyazato J, Horio T, Takiuchi S, Kamide KO, Sasaki S, et al. Left ventricular diastolic dysfunction in patients with chronic renal failure impact of diabetes mellitus, Diabetes UK. Diabetic Med. 2005;22(6)730-736.

doi: $10.1111 /$ j.1464-5491.2005.01500.x [Crossref]

13. Caramori $M$, Fioretto $P$, Mauer $M$. The need for early predictors of diabetic nephropathy risk is albumin excretion rate sufficient?. Diabetes. 2000;49(9)1399-1408.

doi: $10.2337 /$ diabetes.49.9.1399 [Crossref]

14. Younes N, Hanai K, Suzuki K. Comparison of Urinary Albumin-Creatinine Ratio and Albumin Excretion Rate in the Diabetes Control and Complications Trial/Epidemiology of Diabetes Interventions and Complications study clinic. J Am Soc Nephrol. 2010;5(7)1235-1242.

doi: $10.2215 / \mathrm{CJN} .07901109$ [Crossref]

15. Fisher $\mathrm{H}$. Comparison of Associations of Urine Protein-Creatinine Ratio Versus AlbuminCreatinine Ratio with Complications of CKD- A Cross-sectional Analysis. Am J Kidney Dis. 2013;62(6)313-320.

doi: $10.1053 /$ j.ajkd.2013.07.013 [Crossref]

16. Watanabe Y. A Cross-sectional Survey of Chronic Kidney Disease and Diabetic Kidney Disease in Japanese Type 2 Diabetic, Patients at Four Urban Diabetes Clinics. Inter Med. $2009 ; 48(6) 411-414$.

doi: 10.2169/internalmedicine.48.1691 [Crossref]

17. Sanjeev Kumar, Brenner BM, Toto RD. Correlation of DN and HbA1C in Newly Diagnosed Type 2 Diabetic Patients of Western UP. Inter J Sci Res. 2014;4(12)221-225. doi: $10.21276 / \mathrm{ijcmr} .2019 .6 .4 .40$ [Crossref] 
18. Birakta Debbarma, Mohanram A, Zhang Z, Shahinfar $S$, Keane WF. Significance of Microalbuminuria in Newly Diagnosed type 2 Diabetes Mellitus. IOSR J Den Med Sci. $2015 ; 14(8): 40-47$.

doi: $10.9790 / 0853-14814047$ [Crossref]
19. Levey AS, Stevens LA, Schmid $\mathrm{CH}$, Zhang $Y$, Castro $A F$, et al. A new equation to estimate glomerular filtration rate. Ann Intern Med. 2009;150(9)604-612.

doi: $\quad 10.7326 / 0003-4819-150-9-200905050-00006$ [Crossref] 